\title{
Explicitating Structural Shifts in English-Arabic Translation: A Corpus-based Study of the Causal Conjunctives Because and li'anna
}

\author{
Ashraf Abdel Fattah \\ Translation \& Interpreting Institute (TII) \\ College of Humanities and Social Sciences \\ Hamad bin Khalifa University, Doha, Qatar
}

\begin{abstract}
:
This study seeks to contribute to addressing a gap in theory-driven corpus-based research focused on explicitating tendencies in Arabic translated texts. It provides a quantitative and qualitative analysis of the translation of the English causal conjunction because and the use of the corresponding Arabic conjunction li'anna. Adopting a Systemic Functional Linguistics (SFL)based approach, the author analyses bilingual concordance output for the English hypotactic conjunction because, highlighting some interesting patterns of explicitating and upgrading shifts, which for the most part do not seem to be dictated by contrastive linguistic requirements. The study also examines the concordance output of the Arabic causal hypotactic conjunction li anna contrasting it with the corresponding conjunction or construction in the source text. Like a previous study of bilingual concordance output for the English hypotactic conjunction although/though (Fattah, 2016), the present study analyses all conjunctive shifts involving the causal conjunctions because and li'anna, assessing whether, and to what extent, those shifts represent patterns of structural explicitation, which are not attributable to the translator's style, source language/text, or target language requirements.
\end{abstract}

Keywords: Arabic, corpus, explicitation, SFL, translation, upgrading

Cite as: Fattah, A. A. (2018). Explicitating Structural Shifts in English-Arabic Translation: A Corpus-based Study of the Causal Conjunctives Because and li'anna. Arab World English Journal for Translation \& Literary Studies, 2 (1). DOI:http://dx.doi.org/10.24093/awejtls/vol2no1.3 